\title{
LA HETEROGENEIDAD EN LOS RÍOS PROFUNDOS DE JOSÉ MARÍA ARGUEDAS
}

Lucia Herrera Montero ${ }^{1}$

Docente Universidad Politécnica Salesiana y Universidad Andina Simón Bolivar

\section{La pluralidad de voces}

Adentrarse en la novela de Arguedas es sumergirse en profundos y torrentosos ríos donde fluyen voces que se entrecruzan y enfrentan. Es entrar en un espacio discursivo en permanente tensión, en constante disputa, en continua transformación. Arguedas no propone una síntesis conciliatoria y homogénea de la pluralidad; propone un diálogo entre diversos que coexisten, vinculándose y oponiéndose, sin someterse nunca a una instancia que los abarca y concilia, a una síntesis que neutralice las contradicciones existentes.

1 La autora es lingüista; tiene una maestría en Estudios de la Cultura y actualmente está realizando el doctorado en la Universidad de Pittsburg-USA. 


\section{La palabra oral y su poder de encantamiento}

Una de las tensiones fundamentales de Los ríos profundos constituye aquella que se establece entre lo escritural, propio de la novela en tanto forma moderna y urbana, y la oralidad que corresponde a la instancia referencial de la obra. La novela de Arguedas se inscribe dentro de lo que Lienhard denomina la escritura oralizante que corresponde a los "textos que recogen o reelaboran determinados elementos temáticos, enunciativos y poéticos (...) atribuibles al discurso oral de los marginados" (Lienhard, 1995: 15). Pero, en Arguedas, estos momentos orales no constituyen, como en el caso del indigenismo, una simple inclusión dentro de una rigurosa prosa escrita. La oralidad, en Los ríos profundos, está presente más allá de los diálogos y monólogos frecuentes a lo largo de la novela: los estratos orales y los escritos se superponen de modo que los primeros, a decir de Ángel Rama, constituyen la base desde la cual se estructura la obra (Cfr. Rama, 1985).

De este modo, al introducir la oralidad en su proyecto novelístico, Arguedas no solamente reproduce ficcionalmente un sistema comunicativo; se adentra en lo que Guillermo Mariaca (1995: 39) denomina un modo de producción cultural diferente y juega con dos lógicas culturales distintas y heterogéneas. La palabra en Los ríos profundos es la palabra de las sociedades letradas, pero es también la palabra de las comunidades ágrafas: posee capacidad de encantamiento, poder sobrenatural, alcance sacralizador (Rama, 1985: 245). Es una palabra que al nombrar no sólo evoca la realidad sino que la invoca, la vuelve presente. Por ello, el signo lingüístico deja de ser algo puramente arbitrario y convencional para convertirse en magia y conjuro y permitir el acceso a un mundo misterioso de fuerzas naturales y sobrenaturales. 
En la novela de Arguedas (1985: 37), la palabra supera el ámbito de lo humano para invadir todo cuanto se puede concebir. El mundo y sus objetos tienen su propio lenguaje: hablan, cantan y, al hacerlo, despiertan oscuras reminiscencias, transmiten la voluntad y el poder de un mundo que es a la vez visible e invisible a los ojos humanos. Los ríos, por ejemplo, cantan "con la música más hermosa al chocar contra las piedras y las islas". Su voz penetra en la memoria de los hombres y de los pueblos, influye en su destino, determina el curso de los acontecimientos. El Apurímac (Dios que habla) alcanza con su canto las cumbres y despierta en quien lo escucha "los primitivos recuerdos, los más antiguos sueños (...) A los niños los cautiva, les infunde presentimientos de mundos desconocidos" (ibíd.,1985: 23). El Pachachaca (puente sobre el mundo) es un río fuerte y poderoso que, así como puede ser un demonio y destruir, puede también dar consuelo y ser ejemplo de valentía (cfr. ibíd.: 6162). Pero en la novela existen también ríos secos, ríos vacíos durante años, que se hinchan de pronto y "se hacen profundos, que detienen al transeúnte y despiertan en su corazón y en su mente meditaciones y temores desconocidos" (ibíd.: 100).

La palabra invade la naturaleza y la acerca profundamente al hombre. Pero no sólo el ambiente natural tiene su propio lenguaje; los objetos y animales pequeños también adquieren voz en Los ríos profundos. Las campanas, por ejemplo, y en especial la María Angola, provocan prodigios con su tañido: hacen que salgan del agua toros de fuego o de oro, arrastrando cadenas, mientras los viajeros se detienen y se persignan (cfr. ibíd.: 14).

El tankayllu (pequeño insecto) y el pinkuyllu (instrumento musical) poseen voces mágicas: el ruido que el tankayllu produce con sus alas es intenso, "demasiado fuerte para su pequeña figura (...) remueve el aire, zumba 
como ser grande" (ibíd.: 63); por eso los indios creen que en su cuerpo tiene algo más que su sola vida. El pinkuyllu, en cambio, llega con su música muy hondo en el corazón humano (ibíd.: 65). Pero el rey de todos, el mejor, es el zumbayllu: el juguete que canta y con su sonido «aviva en la memoria la imagen de los ríos, de los árboles negros que cuelgan en las paredes de los abismos" (ibíd.: 67). El zumbayllu tiene el poder de llegar a los sitios más recónditos, de llevar mensajes, de alcanzar a los seres queridos. Más si es winko y lay'ka (deforme y brujo) como el que Antero le regaló a Ernesto. Su canto no se quema ni se hiela (...) puede llegar al sol, puede alcanzar al padre de Ernesto, puede cantar para él y darle el mensaje de su hijo. Basta con orientarle el camino y soplar despacito su canto (cfr. ibíd.: 115).

\section{El poder evocador de la lengua de la infancia}

Tankayllu, pinkuyllu, zumbayllu, palabras quechuas cuya terminación produce extrañas analogías. -yllu evoca el canto de los pequeños insectos, pero también la propagación de la música más profunda y la más fuerte (cfr. ibíd.: 63, 65). Fonéticamente, se relaciona con illa, palabra que designa a los seres extraordinarios, cuyo encuentro produce el bien o el mal, pero siempre en grado superlativo. Illa también significa la propagación de la luz no solar. Estas palabras, así como winko o lay'ka, provocan engarces mágicos, se cargan de connotaciones misteriosas y producen, en el nativo hablante que las escucha o pronuncia, extrañas evocaciones emotivas. Así es, para Arguedas, la lengua quechua: una lengua especial que parece traerle dulces reminiscencias de su infancia.

Es importante anotar que para José María Arguedas el quechua constituye la lengua materna mientras que el español es una segunda lengua, aprendida tar- 
díamente. Por esta razón, las palabras quechuas están inmersas en la red de asociaciones emocionales e intelectuales con que fueron empleadas en sus primeros años. La lengua de la infancia, la lengua materna, con la que aprendemos a reconocer y a organizar el mundo que nos rodea, está siempre dotada de una rica polisemia como si...

...sus sonidos fueran capaces de absorber no sólo otros sonidos analógicos o simplemente contiguos, sino también imágenes, olores, sabores y hasta concepciones del universo (...) Las palabras de la lengua de la infancia conservan una arrolladora fuerza asociativa que es capaz de dar saltos mortales entre los más alejados puntos de la realidad, concitando imprevistas asociaciones (Rama, op. cit.: 249).

La fuerza de la primera lengua se explica, según Ángel Rama, por tres rasgos fundamentales:

1. Las palabras en la infancia trabajan sobre un sistema analógico que atiende a los sonidos independientemente de sus significados. En este sentido, existe una relativa independencia de los significantes, que pueden ser relacionados con otros a partir de sus cualidades exclusivamente fonéticas. La vinculación del sufijo - yllu con la palabra illa constituye un claro ejemplo.

2. Durante los primeros años, en el aprendizaje de la lengua materna, no existe distancia entre las palabras y las cosas referidas. El niño reconoce en los signos los objetos que nombra: el ser, el universo y la lengua conforman una unidad indisoluble. El término apakansas, por ejemplo, encierra en él todo el horror de las enormes arañas que designa. 
3. A más de estas relaciones analógicas, se establece una suerte de vinculación metonímica entre las palabras y las cosas. La palabra se vuelve un punto focal que evoca no sólo significados y sonidos semejantes y/o diferentes, sino todo un mundo de objetos y acontecimientos que rodean el momento de su emisión. Ernesto cuenta, por ejemplo, que acompañando en voz baja la melodía de las canciones, se acordaba de los campos y las piedras, de las plazas y los templos, de los pequeños ríos donde fue feliz.

Como lo señala Carlos Pacheco, la obra de José María Arguedas se funda en esa inmensa experiencia infantil de la cultura indígena que hace que la marca de lo oral quede grabada de manera perdurable. La formación bicultural de Arguedas le permite tener un dominio experiencial de las dos culturas y el sentimiento de la doble pertenencia (Pacheco, 1995: 30). Por ello, su escritura no surge tanto de un oficio profesional como de una necesidad de plasmar un mundo insospechado que el conoce íntimamente porque se formó en él y lo amó entrañablemente.

\section{El canto, máxima expresión de la palabra oral en Los ríos profundos}

Ángel Rama propone que la palabra oral de Los ríos profundos encuentra su más alta expresión en el canto. Al leer la novela de Arguedas, constatamos que aparecen intercaladas canciones en quechua con su respectiva traducción española. En esos momentos de alta concentración emocional y artística, la novela está en realidad cantando (Rama, op. cit.) y Arguedas estimula esa sensación a través de múltiples referencias adicionales: descripciones de instrumentos, movimientos y danzas e 
indicaciones sobre la melodía y el ritmo. Así, por ejemplo, nos dice:

... bailaron todos con esa melodía. Zapateaban a compás. Los descalzos, los de ojotas y los de zapatos golpeaban el suelo brutalmente. Los talones de los descalzos sonaban hondo; el cuero de los ojotas palmeaba el suelo duro y los tacos martilleaban (Arguedas: 99).

El ritmo era aún más lento, más triste; mucho más tristes el tono y las palabras. La voz aguda caía en mi corazón, ya de sí anhelante como un río helado (...) el arpa dulcificaba la canción, no tenía en ella la acerada tristeza que en la voz del hombre (ibíd.: 166).

Estos no son paréntesis que rompen la continuidad de la acción; discurren como parte de ella, envueltos en una algarabía generalizada en la que las múltiples voces de la naturaleza, los objetos populares y la vida cotidiana, se encuentran y entrecruzan.

Por otra parte, los cantos reviven la tradición indígena; son básicamente huaynos y jarahuis, canciones de profunda raigambre indígena y popular. Pero no por ser parte de la larga tradición andina evitan la improvisación y la libertad creativa del presente: cuando los soldados persiguen a Doña Felipa, una joven chichera entona un jaylli de Navidad en el que se burla e insulta a los perseguidores. Así, en una canción tradicional, donde la cultura indígena evidencia su identidad, se abre un espacio para la novedad.

En las canciones se entrecruzan la tradición, por un lado, y la historia, con sus conflictos y avatares presentes, por otro. Los cantos representan puntos de contacto del pasado y el presente y focos de transformación cultu- 
ral; tienen la capacidad de religar con el legado ancestral, de conservar la identidad casi mítica de la comunidad y, a la vez, de reintroducir la historia que, en el caso de la novela, está contenida en el plano narrativo.

Las palabras, de este modo, aparecen en estratos superpuestos: en el nivel inferior se encuentra la prosa narrativa, propia del español, explicativa y racionalizada; en un nivel intermedio, el discurso oral del que ya hemos tratado, y en el nivel superior, el canto, y fundamentalmente el canto coral que "establece la unidad dentro de la diversidad” (Rama, op. cit.: 267).

\section{El mundo heterogéneo y conflictivo de Los ríos profundos}

\section{Los símbolos de la diversidad}

En el primer capítulo, Ernesto se encuentra frente al muro incaico, símbolo de la cosmología y la cultura incaicas:

Eran más grandes y extrañas de cuanto había imaginado las piedras del muro incaico; bullían bajo el segundo piso encalado que por el lado de la calle angosta, era ciego. Me acordé, entonces, de las canciones quechuas que repiten una frase patética constante:

yawar mayu, río de sangre, yawar unu, agua sangrienta; puk'tik'yawar k'ocha, lago de sangre que hierve; yawar wek'e, lágrimas de sangre. ¿Acaso no podría decirse yawar rumi, piedra de sangre, o puk'tik'yawar rumi, piedra de sangre hirviente? Era estático el muro, pero hervía por todas sus líneas y la superficie era cambiante, como la de los ríos en 
verano, que tienen una cima así, hacia el centro del caudal, que es la zona temible, la más poderosa. Los indios llaman yawar mayu a esos ríos turbios, porque muestran con el sol un brillo en movimiento, semejante a la sangre. También llaman yawar mayu al tiempo violento de las andanzas guerreras, al momento que los bailarines luchan (Arguedas, op. cit. 8-9).

Es este un párrafo de gran riqueza simbólica: contiene las asociaciones más contradictorias $y$, sin embargo, semánticamente plenas, llenas de sentido o, mejor, de sentidos, que nos remiten a un mundo plural, conflictivo y en perpetua transformación. Encontramos en él una serie asociativa "río-agua-lago-lágrima" que se define por tener como materia común la sangre (Cornejo, 1994: 209). Frente a esta fluidez de elementos líquidos se instala la inmutable solidez de la piedra de manera que el muro incaico se opone y a la vez se desplaza hacia dimensiones que no sólo le son disímiles sino incluso contradictorias.

La piedra deviene líquida, el muro deviene río. Pero si la piedra se vuelve agua, el agua se transforma en sangre: preserva su índole líquida pero transformando, a fondo, su naturaleza y sus significados culturales... de símbolo de vida y pureza se pasa a otro que suele ser asociado con la agresión la violencia y la muerte (ibíd.). Sin embargo, la sangre también es vitalidad, es movimiento, es no-muerte. $\mathrm{Y}$ en este caso, la sangre que hierve deja abiertas, en la consistencia poco definida del vapor, múltiples opciones y posibilidades: podría inclusive ser el hervor de la ira, que genera rebelión, que genera violencia. ¿Hacía dónde irán las masas de colonos que pueden levantarse con tanta fuerza frente a la opresión de la peste y la inminencia de la muerte? ¿Qué tipo de violencia, pro- 
funda y oscura, esconden? ¿Qué ríos de sangre hirviente representan?

Pero toda la vitalidad de esta cultura se halla sometida: el orden arquitectónico así lo evidencia al señalar las jerarquías. Sobre el muro incaico se levanta la pared española, el piso encalado, la fuerza del colonizador. El Cuzco, depositario de la cultura incaica, como el muro, se halla opacado por la civilización de los blancos. De ahí que en Los ríos profundos se perciba la coexistencia de sectores sociales y culturas diversas pero, a la vez, su relación asimétrica: la imposición de una lógica cultural sobre otra, la discriminación, la injusticia, la explotación de amplios grupos indígenas sumidos en la más absoluta miseria.

\section{El sujeto escindido y plural}

La voz narrativa en Los ríos profundos corresponde a Ernesto, un adolescente migrante que cuenta la historia de un momento de su vida. Es pues, desde el punto de vista del narrador en primera persona, una novela autobiográfica que relata una vivencia individual. Sin embargo, esta voz es, también y por la calidad de migrante del narrador, la enunciación de un sujeto múltiple y plural:

...el sentimiento de desarraigo tiene el paradójico efecto de preservar, con intensidad creciente, la memoria del tiempo y el espacio que quedaron atrás, convirtiéndolos en algo así como un segundo horizonte vital que constantemente se infiltra y hasta modela las experiencias posteriores (Cornejo, op. cit., 216). 
El migrante habla desde dos o más lugares de enunciación y multiplica su condición de sujeto. Ernesto es, por tanto, un sujeto escindido entre dos dimensiones sin pertenecer de lleno a ninguna de ellas. El adolescente, en su transición a la madurez, se encuentra en un mundo blanco-mestizo del cual el colegio constituye un microcosmos que reproduce las diferencias, las injusticias, la desigualdad y la discriminación. Pero se halla permanentemente referido a un mundo infantil que "actualiza un mensaje ancestral de armonía y comunión cósmicas" (Jiménez, 1979: 109); de ahí la proliferación de elementos míticos a lo largo de la novela.

Sin embargo, es importante señalar, retomando las palabras de Reynaldo Jiménez, que la propuesta de Arguedas no supone una vuelta al pasado para restituir un orden perdido y una unidad indisoluble con el cosmos. Significa más bien un renacer de esta concepción mítica, un revitalizar de su fuerza ordenadora, pero bajo nuevas condiciones históricas y sociales. No es una nostalgia del pasado, es, por el contrario, una propuesta de futuro que se plasma en la integración a lo que Jiménez llama "nueva colectividad mestiza" y en el resurgir de los valores de la infancia. "La figura de Doña Felipa (una mestiza) se vuelve la representación máxima de la gesta liberadora del pueblo oprimido... Doña Felipa acaba por ocupar en la mente de Ernesto el lugar que antes correspondía a sus protectores del ayllu" (ibíd.: 100).

\section{¿Mestizaje o heterogeneidad conflictiva?}

De lo anterior podríamos suponer, como lo hace Reinaldo Jiménez, que José María Arguedas propone la síntesis de culturas y el mestizaje como la expresión del futuro latinoamericano. Clara Luz Zúñiga (1994: 136) sostiene un tesis parecida cuando afirma que para José 
María Arguedas el mestizaje tiene una función de integración, a la vez social y cultural. Según la autora, "para José María Arguedas, el porvenir del Perú y del pueblo indígena no puede concebirse fuera de un mestizaje social y cultural, donde cada uno de los dos universos transmita a otro lo mejor de sí”.

En una cita en el texto de Clara Luz Zúñiga, José María Arguedas explica:

Somos un país mestizo... Estamos mezclados hasta la raíz. Lo hispánico penetró hasta lo más profundo, sin destruir lo indígena, sin convertir la médula de lo indígena, pero comprometiéndolo, revolucionándolo, en unos segmentos más gravemente que en otros (...) ¿Cómo no he de creer en él, si yo mismo soy mestizo, tan firmemente convencido de su valor? (Zuñiga, ibíd.: 134).

Me parece importante ir más allá de los términos usados y llenarlos del contenido que José María Arguedas efectivamente les otorga. El hablar de una mezcla que no ha logrado transformar las esferas implicadas, el referirse a una interacción que no produce una síntesis plena de las instancias involucradas, supone dotar al término "mestizaje" de connotaciones diferentes a las usuales.

La palabra "mestizo" se usa generalmente para referirse a combinación de factores raciales y culturales que produce una nueva y diferente condición en la que los sectores participantes sufren una completa transformación al integrarse plenamente en el producto resultante. De esta forma se genera una instancia superior, conciliadora y que abarca y subsume las pre-existentes.

En el texto de Arguedas, citado por Clara Luz Zúñiga, podemos apreciar una utilización diferente del término. No hay una completa síntesis sino más bien una 
interacción constante que produce diferentes niveles de transformación e integración así como diferentes grados de compromiso y conflicto. De ahí que se aplique mejor, para la significación dada por José María Arguedas, la noción de "heterogeneidad conflictiva" introducida por Antonio Cornejo Polar.

Para Cornejo Polar, el nuevo sujeto, como el sujeto de Los ríos profundos, tiene una "índole múltiple, dispersa, entreverada, capaz entonces $-\mathrm{y}$ por eso mismo- de abrir una amplia gama polifónica que incluye el sutil tejido de dos idiomas" (Cornejo, op. cit., 215). En este mismo sentido, el mestizaje del que habla Arguedas, es un mestizaje que se evidencia en el muro incaico, en el puente sobre el río Pachachaca, en la María Angola (la campana). Todos estos objetos profundamente simbólicos de Los ríos profundos muestran una integración conflictiva de elementos andinos y españoles; integración que no implica solamente el mantenimiento de múltiples rasgos identitarios sino que evidencia también las profundas contradicciones sociales y económicas que han signado el encuentro de estas dos culturas.

Así, a lo largo de toda la novela se enfatiza en el encuentro y en el desencuentro de diferentes sujetos sociales, culturas y valores. Se propone un espacio discursivo donde los diversos coexisten vinculándose y oponiéndose, un espacio de tensiones y conflictos que hacen imposible tanto un mestizaje armónico como una nostálgica vuelta al pasado indígena. La novela es un espacio discursivo pero también un espacio histórico marcado por la injusticia, la opresión y la miseria. La historia de Ernesto transcurre en medio de la pobreza, en las cocinas de indios, en las letrinas de los colegios, en medio de la basura y de los harapos. Transcurre en condiciones que reflejan la difícil situación latinoamericana y que impo- 
nen, para pensar cualquier posibilidad de futuro, tanto reivindicaciones sociales y económicas como culturales.

Los ríos profundos nos muestra una realidad conflictiva y dolorosa, un mundo totalmente humano, que se va develando a través de una propuesta artística novedosa y bien lograda. Los elementos simbólicos utilizados, el manejo de la oralidad y la incorporación de la magia en la palabra, hacen de Los ríos profundos una ventana poética para acercarse a un mundo hirviente $y$ torrentoso, nombrado por voces diversas, que dialogan y se enfrentan; un mundo formado por materiales disímiles, que interactúan y se transforman incesantemente.

Pero la propuesta arguediana no es sólo una propuesta estética: es también una mirada a una sociedad escindida y desigual, a una región que se debate en la pobreza y la injusticia pero también en la magia y los sueños, y que posee insospechadas capacidades de resistencia y rebelión. La novela de Arguedas nos sumerge así en un espacio conflictivo, pero pleno de significados y de posibilidades. Los ríos profundos nos muestran culturas y seres múltiples y diversos; seres y culturas que no se someten a la síntesis homogenizante del mestizaje sino que coexisten, interactúan y se transforman recíprocamente en un juego inacabado e inacabable, en un hervir continuo, en un choque de aguas torrentosas que se resiste a lo apacible de las aguas quietas y estancadas.

\section{Bibliografía}

ARGUEDAS, José María

1985 Los ríos profundos. Editorial Oveja Negra.

CASTRO KLAREN, Sara

1973 El mundo mágico de José María Arguedas. Lima: IEP.

CORNEJO POLAR, Antonio

1994 Escribir en el aire. Lima: Editorial Horizonte. 
—. Los universos narrativos de José María Arguedas. Buenos Aires: Losada. 1973

HARSS, Luis

1983 "Los ríos profundos como retrato del artista", en Revista Iberoamericana, No 122, enero-marzo.

JIMÉNEZ, Reynaldo

1979 "Realidad y mitificación del narrador niño en Los ríos profundos" en Texto Crítico 14, Xalapa: Centro de Investigaciones Lingüístico-Literarias de la Universidad veracruzana.

LIENHARD, Martín

1995 “Oralidad”. Tucumán: Memorias de JALLA.

MARIACA, Guillermo

1995 "Los refugios de la utopía. Apuntes sobre estudios culturales desde la región andina”. Tucumán: Memorias de JALLA.

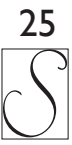

MAZZOTTI, José Antonio

2002 "Heterogeneidad cultural y estudios coloniales: la prefiguración y la práctica de una ruptura epistémica” en Antonio Cornejo Polar y los estudios latinoamericanos, Freidhelm Schmidt-Welle, Ed. Pittsburgh: Universidad de Pittsburgh.

MORAÑA, Mabel

1995 "Escribir en el aire, «heterogeneidad» y estudios culturales”. Revista Iberoamericana N. 170-171. enero-junio.

PERUS, Françoise

1994 Historia y literatura (Introducción). México: Instituto Mora/Antologías Universitarias.

RAMA, Ángel

1985 "La ópera de los pobres" en La crítica de la cultura en América Latina. Caracas: Biblioteca Ayacucho.

—. Transculturación narrativa en América Latina. México: Siglo XXI, 1982.

SCHMIDT-WELLE,Freidhelm

2002 "Heterogeneidad, carnavalización y dialogismo intercultural” en Antonio Cornejo Polar y los estudios latinoamericanos, Freidhelm Schmidt-Welle, Ed. Pittsburgh: Universidad de Pittsburgh.

ZANÍN, Marcela

1995 "La fuerza de la literatura mestiza". Tucumán: Memorias de JALLA.

ZÚÑIGA ORTEGA, Clara Luz

1994 José María Arguedas Un hombre entre dos mundos. Quito: Abya-Yala. 